\title{
Research on the Strategic Design of the Industrial Technological System from the view of Independent Innovation
}

\author{
DING Minglei, CHEN Zhi \\ Chinese Academy of Science and Technology for Development, Beijing 100038, China \\ E-mail: dingml@casted.org.cn
}

KeyWords: industrial technological system, independent innovation, strategic design, industrialization

\begin{abstract}
The development of industrial technological system(ITS) plays an important role in the new round of changes in the world economic structure and technological revolution, also in the path of Chinese industrialization, economic restructuring and sustainable development. Based on the situation and strategic demand analysis for the ITS, the paper discusses the four aspects of problems the ITS faced. It presents a six-point suggestions to promote the construction and development of Chinese ITS from the view of top-level design.
\end{abstract}

\section{Introduction}

The key of national development strategy lies in sticking to a road of independent innovation with Chinese characteristics to boast the capability of independent innovation. The Fifth Plenary Session of the Sixteenth Central Committee of CPC held in October 2005 stipulated the important development strategy of independent innovation, and improvement of the capacity of independent innovation was set as the strategic basis of scientific and technological development and the central link of adjusting industrial structure and transforming growth pattern. After the National Scientific and Technological Innovation Conference in July 2012, it has become the pre-requisite of thoroughly following through on the Scientific Outlook on Development to enhance the capacity of independent innovation and build China into an innovation-oriented country, which also constitutes a significant approach to making breakthroughs in realizing scientific development.

To promote industrial transformation and upgrading, industrial technology progress has become the fundamental driving force behind industrial transformation, upgrading and revolution. Compared with a certain specific technology, industrial technology represents a status of technological evolution in which technology reaches the industrial level and has been systemized. It is a complicated, systemized, competitive and socialized technology that has been transformed into practical productive forces ${ }^{[1][2]}$. Chinese governments at all levels have all increased their support for technological revolution to meet with international financial crisis. The State stipulated ten major industrial adjustment and rejuvenation schemes; National Development and Research Commission and The Ministry of Industry and Information Technology jointly formulated Administrative Measures for Managing Special Investments in Key Industry Rejuvenation and Technological Transformation, in which the guidelines for investing in technological transformation were published. As a result, a batch of key technological transformation projects was made good on. Some local governments integrated national industrial strategies with local conditions, formulated technological transformation and structural adjustment program and set up special auxiliary funds with the view of supporting and guiding enterprise transformation and upgrading in a positive way. From 2009 to 2012, the central government arranged 40 billion RMB worth of special funds for technological transformation, and 8966 projects, which attracted a total investments of 1.021 trillion RMB.

Against the current backdrop of international economic and social development, progress in industrial technology can no longer be achieved through simple breakthroughs in one single technology. It is more often shown in the form of innovations and revolutions in industrial technology system. This system refers to a correlated whole of various technologies and the methods required to acquire and apply these technologies at a certain stage of technological development. It determines 
the main forms of business activities within different departments or businesses through certain combination of systematic arrangements and business models. Its core lies in the creation and transmission of new knowledge and the capability to apply new knowledge to products, service and system. $^{[4]}$ Therefore, the construction and development of industrial technology system plays a significant role in meeting a new round of changes in world economic architecture and technological revolution, embarking on the new industrialization road with Chinese characteristics, completing economic transformation and achieving sustainable development.

\section{The Requirements of China's Construction of Industrial Technology System and Existing Problems}

1. Strategic Demands on Industrial Technology System

Since reform and opening-up was introduced in China, industrial technology system has gone through the following stages: mass-scale introduction, market for technology, combination of independent innovation and open cooperation, etc. For some industries, they developed an extensive way of development at the expense of construction of basic capability of industrial innovation by quickly converting imported mature technology into productivity for a relatively long period. At present, two aspects of restrictions are confronting the implementation of independent industrial innovation strategies: one is systematic upgrading of industrial foundation. The traditional way of technological upgrading in enterprises by substituting backward technology for advanced ones fails to solve systematic upgrading difficulties in industrial foundation, and this is especially so for industries with low intensities; second is generic technological innovation on the level of national strategy. Industrial generic technology is the cornerstone of independent innovation and the source and guarantee of key competitiveness.

2. Existing Problems

This part takes into consideration the historical development of China's industrial technology system and its strategic requirements, and makes an analysis and summarization of the problems that we should notice in the process of transforming our industrial technology system.

First, some industries fail to form an inherent technological innovation system as a result of much too attention to the scale and speed of development, they are forced to update more often than not. ${ }^{[5]}$ Our traditional industrial development mechanism cannot be applied to some high-tech technological industries, and are incongruous with the development rules of some emerging strategic industries. One of the major impetus and successful experiences is for some places to mobilize capital, land and input in R\&D in short term. This method also leads to identity of industries, over-competition, waste of resources, etc. What's more serious is that the imperfect planning and design of the industrial technology system often gives rise to the lack of an inherent technological innovation mechanism, and the industries are forced to upgrade in the international competition. For example, we were unprepared when liquid crystal display technology replaced the cathode-ray tube (CRT) , and had no other choice but to committing ourselves to developing the liquid display industry. This process consumed lots of our human and material resources. And when organic light-emitting diode was about to become the next generation display technology, South Korea went a step ahead of us. This indicates that we are now stuck in the dilemma of passively upgrading.

Second, the construction of industrial technology system is lacking in overall planning and top-design. Institutional arrangements that represent national strategic intentions are inadequate in the construction of industrial technology system and R\&D of industrial generic technology. The functions of management and policy are in charge of different departments and bureaus in the Ministry of Science and Technology, the National Commission on Research and Development and the Ministry of Industry and Information Technology. There is a shortage of an overall design, deployment and coordination based on the national innovation system and revolving around the state innovation development targets and fundamental interests. ${ }^{[6]}$ Therefore, efforts should be made to make mid-long term layout and provide policy support from the state level so that the scale of economy of our technological innovation can be turned into industrial productivity. 
Third, research subject of key industrial generic technology is missing due to wanting long-term stable support. One dilemma facing China's industrial technology innovation is that large amount of industrial generic technology remains to be researched. Individual enterprise is either incompetent or involuntary to undertake major R\&D of major technologies. The innovation subject of industrial technology is missing, leading to low core competitiveness of enterprises. On the other hand, system and mechanism as well as organizational form for combining production, teaching and research cannot meet the requirements of major innovation of industrial technology, and there is not enough strategic cooperation on the level of industrial technology. As a result, the cooperative advantages of innovative network cannot be fully made use of.

Fourth, system integration and collaborative innovation of industrial technology system is insufficient, and innovation ecology remains to be further improved. We pay much attention to breakthroughs in part of technology in neglect of creating sound innovative ecology. And there is also a shortage of systematic and technological innovation and integration innovation in level, structure and relevant technological structures. Core technological capacity highlighted in industrial technology system often comes with breakthroughs in one or several technologies and is based on new technological cluster or new technological system of organic combination of a set of advanced technologies. Take new industries for example. After breakthroughs being made in core technologies of emerging industries, a positive interaction between key unit technology and systematic integration technology is still required, and the same goes for interaction, evolution and perfection of complementary assets and relevant commercial models that are essential for shaping industrial ecological system. Efforts should be made to build mature technological and commercial systems on the applicable level, raise batches of all kinds of technological talents and lead enterprises effectively. Leading enterprises can effectively integrate resources, form a constant innovative ecological system with multiple innovative members through tapping into market demands so as to promote the shaping and development of industries.

\section{Measures and Suggestions}

1. Formulate An Overall Development Planning of Industrial Technology System and Technological System Planning of Key Industries

Given the international industrial competition and the urge of domestic manufacturing industry to become strong instead of large, we should size up the situation, look ahead into the future and formulate relevant plans for developing industrial technology system. Suggestions include the following aspects: one is to set up management departments and institutions for industrial generic technology; second is to establish special funds and development funds for industrial generic technology; third is to adopt different models to found generic technology research institute, and make standard and qualified product evaluation one of the long-term national development strategies; fourth is to accelerate the sharing, promotion and application of industrial generic technology. ${ }^{[7]} \mathrm{At}$ the same time, the construction of an industrial technology system with multiple-input model should be guaranteed, and capital input and usage mechanism be innovated; talent team training and construction mechanism should be innovated; joint development and sharing mechanism of scientific research should be innovated; results sharing and spreading mechanism should be innovated; the supervision and evaluation mechanism should be innovated. The polices, measures and promotion methods that can be employed are as follows: optional finance and taxation, financing support, government R\&D procurement, intellectual property rights protection and accreditation, development of non-profit organizations that support the development of generic technology R\&D.

2. Closely Integrate with the Implementation of National Technological Innovation Project and Regional Innovation System to Identify the Focus of Support and Main Policies and Measures

The construction of industrial technology system should rely on such carriers as national strategic projects and independent innovation demonstration plots and closely integrate the construction of industrial technological innovation system with the implementation of national technological innovation projects and the construction of regional innovation system. Relevant policies should be made based on different categories and in line with China's strategic objectives for industrial 
development and regional development, and policies tools should be adjusted to local conditions. Regions with solid industrial foundations, strong innovative capability and intensive innovation resources can take the lead in establishing some industrial innovation centers in order to play a leading a role.

3. Introduce Guidelines on Accelerating Reform and Development of Transformed Research Institutes and Identify the Strategic Position and Governmental-supporting Methods for Transformed Research Institutes

Under the new circumstances of economic transition and industrial structural adjustment, there is an outcry for transformed research institutes with profound technological accumulation and resource advantages to once again play their powerful scientific leading roles. On the premise of sticking to market mechanism and ensuring competitive dynamics, reform and development of transformed research institutes should be further accelerated to enhance the capability of transformed research institutes to providing society with public technological service. Efforts should be made to pinpoint and strengthen research, development and service of applied supporting technology, key technology, frontier technology, non-profit and industrial generic technology included, so that they can guide the progress and development of industrial technology. The method of government procurement can be employed to provide capital support and subsidies for transformed research institutes that are constructing new-style scientific research institutions.

4. Plan the Construction of a Batch of Industrial Technological Innovative Service Platforms and Testing Bases to Lay Foundation for a New Round of Industrial Upgrading

Focus on major industrial demands to speed up the construction of a batch of service platforms for communal industrial technology innovation; optimize elements allocation to encourage enterprises or enterprise federations to set up testing bases; encourage research institutes in universities, financial organizations and other social entities to establish service platforms for communal industrial technology innovation and testing bases with enterprises. Construction and development of special funds supporting platform and testing bases should be arranged in a planned way step by step in different regions, strategically emerging industrial sectors in particular. Efforts should be made to encourage and support platforms and testing bases to open to society and provide services.

5. Encourage Enterprises to Further Integrate with the International Value Chain to Boost the Emergence of Leading Industrial Enterprises or Enterprise Groups with Leading Innovative Chain and Control Capability

We should encourage enterprises to blend in the global value chain through in-depth cooperation on their own so as to acquire information related with technology and global market changes in a more direct way and accumulate innovative and upgrading capability. We should actively guide and promote industrial integration so as to form innovative-chain-guided enterprises with control capabilities. In this way they can play their leading roles in innovation, technological demonstration and internet radiation, etc., as well as actively extend functions toward the two ends of the value chain, resulting in improved capability to participate in global value chain competition. Take Longing Environmental Protection Ltd. Co, a leading enterprise in the machinery industry for environmental protection, for example. It came up with an enterprise development strategy and development plan of "forging state-of-the-art total industrial package of innovative environmental protection". At the same time, we should encourage multi-national enterprises to set up research centers in China or transfer their core technological R\&D to China in order to motivate the innovative vigor of private enterprises. We should support enterprises in carrying out international scientific and technological cooperation and exchanges and going out to set up oversea R\&D centers so that they can guide, participate in and undertake $\mathrm{R} \& \mathrm{D}$ and effective transition of international high-standard achievements.

\section{References}

[1] Yuan Deyu. Definition of Industrial Technology. College Journal of Northeastern University (Science and Technology Edition), 2000, 2(1): 22-25 
[2] Ding Yunlong. What’s Industrial Technology? Science and Dialectics, 2002, 19 (4): 35-39

[3] Development Research Center of State Council. Accelerate the Construction of Long-term Mechanism in Support of Enterprise Technology Renovation. Investigation Research Report, the 98th Issue of 2012

[4] Ikujiro Nonaka, Hirotaka Takeuchi. Knowledge-creating Industry: the Driving Forces behind Constant Innovation of Japanese and American Enterprises. Beijing: Intellectual and Property Publishing House, 2006

[5] Development Research Center of State Council. Pinpoint Supporting Focus: Promote the Upgrading of China's Display Industry. Investigation Report. 100th Issue of 2012

[6] Kong Xinxin, Wang Fenyu. Construct New-style Department Innovation System and Promote the Reform of “Giant Department System”[R]. Investigation Report, 18th Issue of 2008

[7] Lu Yansun. Omission of Research on Fundamental Industrial Generic Technology [R]. Report of Symposium on Deepening the Reform of S \& T Innovation Mechanism of the Energy and Power Equipment Manufacturing Industry. October 29, 2011. 